\title{
Correspondence
}

\section{Anaemia and child health surveillance}

Sir,

Professor Illingworth's 'state of the art' review of iron deficiency anaemia ${ }^{1}$ raised important issues of prevention but poses more questions than it answers, some of which are addressed in a recent Lancet editorial. ${ }^{2}$ Should haemoglobin estimation be a screening test in childhood, and if so what technique should be used? What dietary strategies might best prevent anaemia (and the accompanying psychomotor delay)? There is also a wider question: what investigations should be available for children at primary care level, and should they be in general practitioner surgeries or clinics, or both?

It would be good to see a consensus emerging from within the British Paediatric Association on these questions to guide primary care practice. Some basic community research will be needed, however, to establish: (1) the best age to test for anaemia; (2) the most suitable technique to use and whether it will be clinic or central laboratory based; (3) the nature of the diet that leads to anaemia in different populations; and (4) the acceptability and practicability of a blood test as part of routine surveillance. Quality control is the stumbling block in establishing peripheral diagnostic facilities such as haemoglobin estimation, urine microscopy, and stool analysis, but the esculating demands on hospital laboratory services must surely point us in this direction.

\section{References}

1 Illingworth R S. Anaemia and child health surveillance. Arch Dis Child 1986;61:1151-2.

2 Anonymous. Iron deficiency - time for a community campaign? [Editorial]. Lancet 1987;i:141-2.

T WATERSTON Community Health Service, Newcastle General Hospital, Newcastle upon Tyne NE4 $6 B E$

\section{Age specific xerophthalmia rates among displaced Ethiopians}

Sir,

In his paper Dr Pizzarello reports the eye signs that he found in 1200 displaced Ethiopian children and that he attributed to vitamin A deficiency. ${ }^{1}$ The results were analysed by sex and for age groups $0-6$ years and 7-14 years. The rates of Bitot's spots and corneal xerosis in all groups, as well as those for keratomalacia and corneal scars, far exceeded those suggested by the World Health Organisation (WHO) ${ }^{2}$ as criteria for recognition of a public health problem. His conclusion that vitamin A deficiency was a serious problem in those aged 7-14, as well as in those aged $0-6$, must not be allowed to go unchallenged. Interestingly enough, the first clear demonstration of the lack of relation between Bitot's spots and active vitamin A deficiency in school age children was carried out nearly 30 years ago in Ethiopia. ${ }^{2}$ This observation has since been repeatedly confirmed from other parts of the world. ${ }^{34}$ At least some of the Bitot's spots in older children seem to be stigmata of vitamin A deficiency in the past, ${ }^{5}$ and this may account for the rise in incidence with increasing age, commonly reported, as here. This is why WHO insisted that the subject group for prevalence surveys should be preschool age children. ${ }^{2}$

Another disturbing feature of this paper concerns the other criterion for coming to this conclusion-namely, corneal xerosis (X2). During the many discussions that I have had over the years with other workers experienced in the ocular manifestations of vitamin A deficiency, it has always been agreed that X2 (as the most advanced eye change present) is quite rare, probably because it advances rapidly to keratomalacia (X3A or B). Furthermore, without a slit lamp it is usually difficult to know whether or not a cornea is xerotic. For these reasons X2 is included with $\mathrm{X} 3 \mathrm{~A}+\mathrm{B}$ in the WHO criteria. ${ }^{2}$ The high incidences for $\mathrm{X} 2$ reported here are most unusual. All of this is not to minimise the serious problem of the occurrence of vitamin A deficiency in refugee populations. Although the WHO guidelines have not been engraved on tablets of stone, they have been drawn up after prolonged and detailed consideration of the available evidence. They should be read carefully and followed strictly; if then they can be shown to be in need of revisions this will happen if new data necessitate it.

Figures 1 and 2 have been incorrectly labelled.

\section{References}

' Pizzarello LD. Age specific xerophthalmia rates among displaced Ethiopians Arch Dis Child 1986;61:1100-3.

2 Report of a joint WHO/UNICEF/USAID/HKI/IVACG meeting. Control of vitamin A deficiency and xerophthalmia. WHO Tech Rep Ser 1982; No 672.

3 Paton D, McLaren DS. Bitot spots. Am J Ophthalmol 1960;50:568-74.

${ }^{4}$ Sommer A. Nutritional blindness:xerophthalmia and keratomalacia. New York: Oxford University Press. 1982.

${ }^{5}$ Sommer A, Emran N. Tjakrasudjatma S. Clinical characteristics of vitamin A responsive and nonresponsive Bitot's spots. Am J Ophthalmol 1980;90:160-71.

Donal.d Mclaren Royal Infirmary, Edinburgh EH3 $9 Y W$ Scotland

Dr Pizzarello comments:

I agree with Dr McLaren that the rates of xerophthalmia in the age group 0-6 far exceeded WHO guidelines but 
consider that the data support the presence of the disease in older children as well. Clearly, Bitot's spots do not always indicate the presence of active xerophthalmia in children over 6 , a point made in the original paper. The extent of severe malnutrition in all age groups prompted me to examine children up to 14 in this population. It was an unprecedented situation, which I thought merited a wider sample size than normally used.

While Dr McLaren thinks that corneal xerosis cannot be diagnosed without a slit lamp, numerous other investigators have reported corneal xerosis in prevalence surveys performed without a slit lamp. In fact, the WHO Field guide to the detection and control of xerophthalmia' states that (corneal xerosis) is easily diagnosed and highly specific' and makes no mention of the use of a slit lamp to make this diagnosis. ${ }^{1}$ I feel confident in the diagnosis as stated in the paper.

Finally, and most disturbing, is the point made by $\mathrm{Dr}$ McLaren that while the WHO guidelines are not engraved on stone tablets, they should stand until new data become available. The point of this paper is to suggest that in severe disaster situations just such a revision may be indicated. It is time for this issue to be discussed in an open forum to prepare for the next disaster, which most unwelcomely and assuredly will arise.

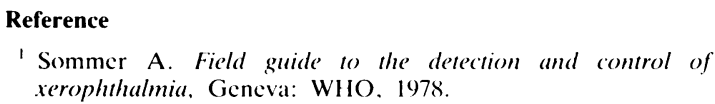

' Sommer A. Field guide to the detection and control of xerophthalmia. Geneva: WHO. 1978.

\section{Meningitis presenting as hypertension}

Sir.

I have just read the report by Waters and Gillis of meningitis presenting as hypertension.' A month ago I was called urgently to see a child with haemophilus meningitis who had developed severe hypertension. The hypertension was cured instantly by using an appropriately sized sphygmomanometer cuff. Reports involving blood pressure measurement in children should always give precise details of how the blood pressure was measured.

\section{Reference \\ 1 Waters K, Gillis J. Meningitis presenting as hypertension. Arch Dis Child 1987:62:191-3.}

D P ADDY

Postgraduate Centre, Dudley Road Hospital, Birmingham Bl8 $7 \mathrm{QH}$

\section{Meningitis due to Haemophilus influenzae type $\mathrm{b}$ resistant to ampicillin and chloramphenicol}

Sir,

The recent report by Fraise et al of multiply resistant Haemophilus influenzae $e^{1}$ akes reference to two previous reports of resistance found in this organism from the United Kingdom ${ }^{2}$ and the United States. ${ }^{3}$ I suspect the authors did not take the time to read the reference for the USA. If they had it would have been clear that it was describing resistance in Australia, a country not easily confused with the USA. Even correct reading of the title should have made the error apparent.

Chloramphenicol resistance is now widespread, including reports from Thailand, ${ }^{4}$ the USA, ${ }^{5}$ and the Caribbean."

Readers are entitled not only to accuracy of data but also to diligence and care of presentation.

\section{References}

1 Fraise AP. Mecks ACG. Richards JE. Meningitis due to Hacmophilus influenzac resistant to ampicillin and chloramphenicol. Arch Dis (hild 1986:61:1134-5.

- Garvey RJP. McMullin GP. Meningitis due to beta lactamase producing type b Hacmophilus influenzac resistant to chloramphenicol. Br Med J 1983:287:1183-4.

3 Hansman D. Forsyth K. Multiply resistant Haemophilus infuenzac - South Australia. Communicable Diseases Intelligence 1985:1:2-3

+ Simasathien S. Duangmani C. Echeverria P. Haemophilus influenzac type b resistant to ampicillin and chloramphenicol in an orphanage in Thailand. Lancet 198():ii:1214-7.

5 Uchiyama N, Greene G, Kitts D. et al. Meningitis due to Hacmophilus influenzac type $b$ resistant to ampicillin and chloramphenicol. J Pediatr 1980:97:421-4.

"Anonymous. Ampicillin and chloramphenicol resistance in Haemophilus influenzate disease (Editorial). MMWR 1984; 33:35-7

Kevin Forsyth

Flinders Medical Centre. South Australia 5042

Drs Fraise, Meeks, and Richards comment:

We have read with interest the comments made by $\mathrm{Dr}$ Forsyth. We acknowledge that there was an omission in the introductory phrase of our paper, which should have read . . . . in the United States and in Australia.' We do not believe a small omission such as this, however, changes in any way the validity of our report or the message it contains.

This correspondence is now closed-ed.

\section{Thrombotest values and effect of vitamin $\mathrm{K}$ administration for infants}

Sir.

The finding of Garrow et al that Thrombotest values decline on the second day of life in breast fed babies but not in those who have received vitamin $\mathrm{K}$ at birth is important.' Fetal haemorrhagic episodes, including intracranial haemorrhage, are more common at 2 to 3 weeks of age than in the early days of the neonatal period. ${ }^{2}$ Thus the Thrombotest for babies at 2 weeks may also be useful to predict and manage vitamin $\mathrm{K}$ deficiency.

We performed the Thrombotest (Thrombotest Owren Eisai Co, Tokyo) for 437 babies at 2 weeks. Of the 437 babies, 263 were breast fed, 37 bottle fed, and 137 mixed 